\title{
Adolpho Lutz e a história da medicina tropical no Brasil
}

\section{Adolpho Lutz and the bistory of tropical medicine in Brazil}

\author{
Jaime Larry Benchimol e Magali Romero Sá \\ Pesquisadores da Casa de Oswaldo Cruz \\ Av. Brasil, 4365 \\ 21045-900 Rio de Janeiro - RJ \\ jben@coc.fiocruz.br e magali@coc.fiocruz.br
}

Johann Becker

Prof. titular do Museu Nacional da Universidade Federal do Rio de Janeiro

Talita Gross, Márcio Magalhães de Andrade e

Paulo Cesar Gil Ferreira Junior

Bolsistas do CNPq

Mônica de Souza Alves da Cruz, Tatiana da Silva Bulhões e Victor Leandro Chaves Gomes

Pesquisadores contratados

Este texto apresenta um balanço das atividades do projeto sobre Adolpho Lutz e a
história da medicina tropical no Brasil: o andamento da preparação dos textos e da
correspondência do cientista para publicação, a descrição e o tratamento dos
componentes de seu arquivo, que se acha sob a guarda do Museu Nacional. Traz como
anexos a relação dos cargos, títulos, prêmios e condecorações de Adolpho Lutz, sua
bibliografia e uma seleção de cartas recebidas por ele.
PALAVRAS-CHAVE: Adolpho Lutz, medicina tropical, Bertha Lutz, Museu Nacional, correspondência.

This text presents an evaluation of the activities of the Adolpho Lutz project and a history of tropical medicine in Brazil: progress in the preparation of texts and Lutz's correspondence forpublication, the description and treatment of components of his papers, which are found at the National Museum. Appendices iclude a list of posts, titles, awards and decorations received by Adolpho Lutz, his bibliography and a selection of letters received by him.

KEYWORDS: Adolpho Lutz, tropical medicine, Bertha Lutz, Museu Nacional, correspondence.

$\mathrm{H}$ á quem considere Adolpho Lutz (1855-1940) o mais importante cientista brasileiro. Superlativos à parte, é, certamente, um dos menos estudados entre os nomes que compõem o panteão de nossas ciências. Adolpho Lutz foi o mais importante elo de ligação entre a 
Escola Tropicalista Bahiana e a medicina pós-mansoniana. Com o estudo fundamental sobre o Ancylostoma duodenale, que publicou em Leipzig, em 1885, e no Brasil, na mesma década, pôs a agenda de pesquisa helmintológica, inaugurada por Otto Wucherer, em sintonia com o arsenal teórico e metodológico dos microbiologistas alemães, franceses e ingleses. Já havia publicado, então, trabalhos sobre zoologia, clínica e terapêutica durante os anos de formação na Suíça e Alemanha. Em Limeira, interior de São Paulo, inaugurou os estudos parasitológicos sobre doenças animais. De volta à Alemanha, em 1886, enveredou pela bacteriologia da lepra, e estes estudos o levaram à direção do leprosário de Molokai, no Havaí, onde desembarcou no dia em que caiu a monarquia brasileira.

Até assumir a direção do Instituto Bacteriológico de São Paulo, em 1893, Adolpho Lutz percorreu diversos espaços geográficos (Rio de Janeiro, São Paulo, Europa, Estados Unidos, Oceânia) e cognitivos (clínica médica, helmintologia, bacteriologia, terapêutica, veterinária, dermatologia, protozoologia, malacologia, micologia, entomologia). Deixaria marcas duradouras de sua passagem nos estudos sobre o mormo, mal-das-cadeiras, osteoporose dos cavalos, plasmodiose das vacas, parasitoses de animais silvestres e domésticos, lepra, ancilostomíase, febre amarela, tuberculose, doenças de pele etc. O período em que esteve à frente do Bacteriológico caracteriza-se por intensa atividade de pesquisa em laboratório, combinada com ações de grande envergadura na saúde pública: campanhas sanitárias, estudos epidemiológicos e duras controvérsias envolvendo, sobretudo, a febre amarela urbana e silvestre (que anteviu), a malária das zonas paludosas e também das florestas serranas (que descobriu), o cólera, a febre tifóide e a peste bubônica.

Ao se transferir para o Instituto Oswaldo Cruz (IOC), em 1908, com 53 anos, era um profissional mais maduro do que os jovens médicos recrutados por Oswaldo Cruz, todos na casa dos vinte anos. Trazia larga experiência como sanitarista e bagagem considerável de trabalhos científicos em todas as vertentes da chamada medicina tropical, o que levaria Arthur Neiva a classificá-lo como "naturalista genuíno da velha escola darwiniana". Tal polivalência torna-o personagem-chave para se rastrear a evolução e o entrelaçamento das problemáticas científicas no âmbito da medicina experimental do último quartel do século XIX a meados do XX.

Nos anos 1950, por ocasião da celebração do centenário de seu nascimento, as Memórias do Instituto Oswaldo Cruz e a Revista do Instituto Adolfo Lutz veicularam trabalhos escritos por cientistas e pelos filhos de Adolpho Lutz - Bertha e Gualter — focalizando aspectos de sua trajetória. Mais recentemente, o cientista foi objeto de estudos parciais na obra comemorativa do centenário do Instituto Adolfo Lutz. De resto, o que há são referências mais ou menos passageiras em teses, livros e artigos que tratam de instituições, personalidades e políticas 
médicas e científicas, pouco acrescentando aos conhecimentos sobre Adolpho Lutz reunidos nos estudos citados.

$\mathrm{Na}$ última década, a história das ciências e, em particular, a das ciências da vida, experimentou verdadeiro boom acadêmico, com a publicação de numerosas teses, livros e artigos. A publicação dos trabalhos dispersos de Adolpho Lutz, associada a um estudo sobre o cientista mais afinado com as diretrizes metodológicas que guiam a produção contemporânea em história das ciências, são iniciativas importantes para a história das doenças, a história das políticas e instituições de saúde e para a expansão de linhas de pesquisa ainda incipientes entre nós, como a história da parasitologia, veterinária e zoologia médica.

O projeto Adolpho Lutz e a História da Medicina Tropical no Brasil tem por objetivos a edição crítica e comentada da obra de Adolpho Lutz; a elaboração de estudos sobre a história da medicina tropical no Brasil, entre as décadas de 1880 e 1940, tendo em vista a contextualização de sua trajetória; e a elaboração de ensaio biográfico sobre o cientista a ser incluído nos volumes a publicar.

Os resultados da primeira fase do projeto foram viabilizados com recursos oriundos de três fontes. Em março de 2000, solicitamos auxílio integrado ao Conselho Nacional de Desenvolvimento Científico e Tecnológico (CNPq), atendendo aos termos de um edital que foi cancelado, concedendo aquela agência apenas as bolsas, a partir de agosto. Em janeiro de 2001, obtivemos os recursos solicitados para a execução do projeto. Neste ínterim, ele foi submetido ao Programa Estratégico de Pesquisa (PEP) da Casa de Oswaldo Cruz, da Fundação Oswaldo Cruz (COC/Fiocruz), que também o aprovou (setembro de 2000). Obtivemos ainda auxílio integrado da Fundação de Amparo à Pesquisa do Estado do Rio de Janeiro (Faperj), em março de 2001.

Ao vencer o prazo de vigência destes recursos, apresentamos os seguintes resultados:

- Estão prontos os trabalhos de Adolpho Lutz que vão compor o primeiro volume de sua Opera omnia, prevendo-se a entrega à Editora Fiocruz do material já revisto e editorado no começo de 2003.

- Boa parte da correspondência está traduzida e digitada, com revisão técnica adiantada.

- Índices remissivo e onomástico do primeiro volume em fase adiantada de elaboração.

- O acervo encontra-se higienizado, mecanicamente, e arrumado fisicamente em caixas, pastas e maços. Foram incorporados ao Arquivo Adolpho Lutz os maços de documentos provenientes do Arquivo Bertha Lutz, que dizem respeito a seu pai. O conteúdo das pastas e maços foi objeto de uma primeira descrição abrangente, tendo sido concluída a revisão final das caixas e pastas concernentes 
aos temas selecionados para os dois primeiros volumes da obra de Adolpho Lutz.

- Oitenta e cinco por cento da correspondência acha-se descrita em banco de dados informatizado, tendo sido iniciado o cadastramento das separatas pertencentes originalmente à biblioteca de Adolpho Lutz.

- Realização de entrevistas, já transcritas e editadas.

- Armazenagem, em forma digital, de interessante iconografia sobre Adolpho Lutz localizada no Departamento de Documentação da COC, nos acervos de Bertha Lutz e Adolpho Lutz, no Museu Nacional; no Instituto Adolfo Lutz e no Museu Emílio Ribas, em São Paulo.

O projeto prossegue, a pleno vapor, com recursos de duas novas fontes de financiamento: o Programa de Apoio à Pesquisa Estratégica em Saúde (PAPES III), da Fiocruz, cujo apoio obtivemos em agosto de 2002, depois de vencer concorrência interna de projetos de pesquisa; e o Instituto Adolfo Lutz, que está em vias de iniciar colaboração no custeio de mais quatro volumes da Opera Omnia de Adolpho Lutz: dois ainda com trabalhos inéditos ou publicados pelo cientista; um volume com sua correspondência; e o volume final, contendo ensaios de cientistas que atuam nas várias disciplinas em que Lutz se destacou, com análises sobre a importância e atualidade de sua obra.

Com recursos porporcionados pelas emendas parlamentares dos deputados Jandira Feghali, Fernando Gabeira, Jorge Bittar, Miro Teixeira e Alexandre Cardoso custearemos este empreendimento, que é caro, e que se desdobrará nas seguintes frentes: criação de uma Biblioteca Virtual Adolpho Lutz nos moldes das que a COC já criou para Carlos Chagas (http://www.prossiga.br/chagas/), Oswaldo Cruz (http:// www.prossiga.br/oswaldocruz/) e Vital Brazil (http://www.prossiga.br/ vitalbrazil/); e realização de exposição e ciclo de palestras sobre Adolpho Lutz e a história da medicina tropical no Brasil.

\section{Desenvolvimento do projeto}

O projeto começou a ser executado em agosto de 2000. Tirando proveito de convênio existente entre a COC e o Museu Nacional, instalamos a equipe e a documentação de Adolpho Lutz, ainda misturada à de sua filha, Bertha Lutz, em pequena sala situada dentro do depósito da biblioteca central do Museu, onde encontramos livros, separatas e documentos pertencentes a dois personagens importantes na vida de Adolpho Lutz, os cientistas Ângelo Moreira da Costa Lima e Arthur Neiva, do IOC.

Quando afluíram os recursos do CNPq, adquirimos três computadores e uma impressora, que funcionam em rede, conectada à rede geral do Museu (alutz@brfree.com.br). A equipe foi até agora constituída pelos bolsistas de iniciação científica Paulo Cesar Gil Ferreira Junior (até 
agosto de 2002) e Tatiana da Silva Bulhões (graduandos de história), e o bolsista de aperfeiçoamento técnico Márcio Magalhães de Andrade, historiador - as três bolsas custeadas pelo CNPq. Com recursos do PEP, foram pagos os serviços de Talita Gross, graduanda de literatura alemã (que agora desfruta da bolsa anteriormente concedida a Paulo Cesar), Victor Leandro Chaves Gomes, historiador, e Morgana Barison, substituída em março de 2002 por Mônica de Souza Alves da Cruz, historiadora também.

Beth Cobra, profissional com larga experiência em edição de periódicos científicos (trabalhou durante muitos anos na Dados) incorporou-se à equipe em junho de 2002, em tempo parcial, para auxiliar nos trabalhos de edição dos volumes projetados. Desde maio, Irene Fachini Souza vem se dedicando, prioritariamente, à digitação dos numerosos documentos selecionados para publicação.

Anne Caroline de Carvalho Nunes e Bruno Perrone da Rocha, profissionais com experiência em arquivos e documentação, foram contratados, por três meses (agosto-outubro) para fazer a revisão final da descrição dos conteúdos das pastas e maços de documentos do Acervo Adolpho Lutz, e a armazenagem em pastas de maços recémextraídos do Arquivo Bertha Lutz.

Outros profissionais têm prestado serviços ao projeto (tradução, digitação, transcrição de fitas, revisão, informática etc.). André Vieira de Campos, pesquisador visitante da COC e professor das universidades Federal Fluminense (UFF) e do Estado do Rio de Janeiro (UERJ), utilizou o projeto como laboratório de aprendizagem para alunos de graduação em história, desta última universidade, com resultados proveitosos para nós. Temos contado com a valiosa colaboração das dras. Charlotte e Margarete Emmerich (antropóloga e botânica, respectivamente), Ortrud Monika Barth Schatzmayr (virologista), e dos profs. Johann Becker e Nelson Papavero (zoólogos) na revisão técnica das traduções.

A dinâmica dos trabalhos não permitiu ainda que estabelecêssemos as parcerias desejadas com os pesquisadores que, de acordo com o projeto original, usariam a documentação de Adolpho Lutz para redigir ensaios parciais analisando em profundidade aspectos de sua trajetória científica. Cremos que tais parcerias serão possíveis quando tivermos o acervo plenamente consolidado, e concluída a preparação dos originais dos volumes da obra do cientista. A intervenção de pessoas que não fazem parte da equipe no espaço precário e na documentação no estado em que se encontra pode gerar problemas logísticos capazes de comprometer o êxito das metas básicas do projeto.

Os acervos de Adolpho e Bertha Lutz interpenetravam-se, e por isso tivemos de extrair materiais concernentes ao pai de dentro das gavetas e pastas que continham a documentação da filha. Ela é personagem muito importante na trajetória de Adolpho Lutz, e o tratamento de um acervo tem requerido trabalhos em proveito do outro. A história da Bertha Lutz cientista tende, inclusive, a se tornar 
um desdobramento do projeto atual. Principiam colaborações com as dras. Maria Margareth Lopes, do Instituto de Geociências da Universidade Estadual de Campinas (Unicamp), que tenciona estudar a trajetória de Bertha como cientista, e Nara Brito, da COC, que está formando uma equipe para investigar as mulheres cientistas no Brasil.

O acervo de Adolpho Lutz é constituído por numerosos documentos manuscritos e datilografados, e por boa parte dos trabalhos que publicou, e que se encontram aí sob a forma de exemplares avulsos de periódicos, separatas, cópias fotostáticas, textos transcritos, originais manuscritos ou datilografados, provas tipográficas revistas etc. Excetuando-se a fração (minoritária) de materiais por nós incorporada ao acervo, ele foi reunido por Bertha Lutz, com a ajuda do irmão, Gualter Adolpho Lutz, professor catedrático de medicina legal da Faculdade de Medicina do Rio de Janeiro. Além de ativa militante feminista, Bertha era bióloga e dedicou-se a vida toda ao estudo dos anfíbios anuros, uma das linhas de investigação do pai. Durante os últimos anos de vida dele, quando, praticamente cego, não conseguia mais ler nem escrever, esteve a seu lado, continuamente, ajudando-o a redigir os derradeiros trabalhos que publicou. Adolpho Lutz faleceu em 6 de outubro de 1940, poucas semanas antes de completar 85 anos. Em dezembro de 1955, o centenário de seu nascimento foi comemorado no Rio de Janeiro e em São Paulo por diversas instituições científicas, prevendo-se, então, a publicação de sua obra, o que não aconteceu, apesar dos esforços envidados por Bertha Lutz. Após a morte do pai, empenhou-se por reunir os trabalhos e a correspondência que se encontravam em poder de cientistas, instituições e periódicos de diversos países com os quais se relacionara. Um dos componentes do acervo consiste, justamente, na correspondência de Bertha com os detentores destes materiais, e com os possíveis patrocinadores do projeto de publicação da obra de Adolpho Lutz. Pesquisadora do Museu Nacional, Bertha passou a ocupar o laboratório do pai no IOC, após seu falecimento. Atritos com cientistas desta instituição levaram-na a transferir para a Quinta da Boa Vista não apenas o acervo, mas boa parte das coleções formadas por Adolpho Lutz. Quando Bertha faleceu, em setembro de 1976, seu arquivo pessoal e o de Adolpho Lutz foram atirados ao limbo, e durante muitos anos vagaram por corredores e laboratórios do Museu Nacional, sujeitos a variados agravos, até serem resgatados da destruição iminente por Magali Romero Sá.

Antes de darmos início à preparação dos originais da obra de Adolpho Lutz e dos ensaios analíticos sobre o cientista, tivemos de cuidar da organização e catalogação de seu acervo. Separamos os materiais de Adolpho e Bertha Lutz. Recuperamos e expandimos a ordenação criada por ela, de caráter predominantemente temático. Acondicionamos os documentos em pastas, caixas e estantes adequadas, tendo antes o cuidado de providenciar a higienização 
dos documentos. Fizemos, a princípio, a descrição sumária da documentação, e estamos perto de concluir a descrição pormenorizada do conteúdo dos maços contidos em cada uma das 286 pastas. Incluem alguma iconografia, porém em volume muito menor do que a documentação manuscrita, datilografada ou impressa.

Os temas que servem como elementos de ordenação do material reunido nas pastas são, em primeiro lugar, os vários campos disciplinares em que Adolpho Lutz atuou:

- helmintologia (cestóides, trematódeos, oligoquetas, nematelmintos como tênias, ascarídeos, fascíolas, ancilóstomos, esquistossomo, Echinostoma, Drepanidium);

- entomologia (tabanídeos, simuliídeos, culicídeos);

- malacologia (Biomphalaria e Physa, sobretudo);

- micologia;

- dermatologia;

- herpetologia (cobras e anfíbios);

- protozoologia;

- outros domínios da zoologia: aves e mamíferos;

- botânica.

Lutz é considerado o pioneiro dos estudos em veterinária no Brasil, constituindo este mais um tema do acervo. Traço marcante de sua trajetória é a combinação de grande versatilidade e erudição nos domínios da história natural e biologia com o engajamento médico e sanitário. Teve, assim, importante atuação como clínico e sanitarista, realizando investigações em campo e em laboratório nas áreas da clínica médica, anatomia patológica, bacteriologia e medicina tropical. Publicou importantes trabalhos e manteve ativa correspondência sobre doenças bacterianas e doenças transmitidas por insetos sugadores de sangue e outros hospedeiros, especialmente:

- febre amarela;

- malária;

- lepra;

- micoses;

- peste bubônica;

- disenterias;

- cólera;

- febre tifóide;

- esquistossomose.

Outras doenças são contempladas no acervo, ainda que nem todas dêem nome a pastas específicas. É o caso de tuberculose, beribéri, bouba, raiva, bócio, doença de Chagas, enfisema, leishmaniose, difteria etc. Parte da documentação diz respeito a um terceiro conjunto de temas: 
- Métodos e técnicas de pesquisa e diagnóstico laboratorial, e de captura e tratamento de espécimes destinados a coleções e estudos zoológicos.

- Viagens científicas.

- Relação com colecionadores, bem como leigos e especialistas que capturavam espécimes para Lutz, ou que produziam desenhos e gravuras de animais estudados por ele.

- Correspondência com sociedades e instituições científicas nacionais e estrangeiras.

- Documentação concernente às comemorações do centenário do nascimento de Adolpho Lutz e a outras celebrações e homenagens.

Os artigos científicos de Adolpho Lutz — em separatas, opúsculos, recortes de jornal, ou em cópias fotostáticas e xerográficas - foram armazenados em caixas segundo uma ordenação cronológica. Nas pastas temáticas encontram-se cópias datilografadas por ordem de Bertha de alguns trabalhos publicados ou mesmo inéditos, assim como manuscritos e/ou provas tipográficas revistas pelo autor e materiais utilizados como insumos dos artigos que publicou. As publicações de Adolpho Lutz são listadas em documento no qual constam algumas ligações entre o que está ordenado cronologicamente nas caixas e, tematicamente, nas pastas.

O Acervo Adolpho Lutz inclui número ainda não contabilizado de separatas, revistas, opúsculos, relatórios e livros que faziam parte de sua biblioteca. Achavam-se, provavelmente, em seu laboratório, no IOC. Essas publicações foram higienizadas e arrumadas em estantes, mas apenas recentemente iniciamos sua catalogação.

Paralelamente ao tratamento e à descrição do conteúdo das caixas de documentos, providenciamos a montagem de um banco de dados em Access, com planilhas para registrar, peça a peça, a correspondência ativa e passiva de Adolpho Lutz (cartas, ofícios, bilhetes, cartões etc.), com ferramentas de busca, formatos de impressão de relatórios etc. Aproximadamente 85\% da correspondência está registrada nesse banco de dados. Segundo o último levantamento, há 3.847 itens na base, dos quais 1.864 com sumário e 1.983 sem. Foram traduzidas 293 cartas, e 19 aguardam tradução.

Já iniciamos a revisão dos 3.847 registros atualmente existentes na base de dados.

CORRESPONDÊNCIA SEGUNDO IDIOMAS

\begin{tabular}{ll}
\hline IDIOMA & No DE CARTAS \\
\hline Alemão & $1.159(527$ com sumário $)$ \\
Espanhol & $169(129$ com sumário $)$ \\
Francês & $175(15$ com sumário $)$ \\
Inglês & $969(566$ com sumário $)$ \\
Italiano & $30(5$ com sumário $)$ \\
Português & $1.049(678$ com sumário $)$ \\
\hline Total & $\mathbf{3 . 5 5 I}$ \\
\hline
\end{tabular}


Além de havermos higienizado, catalogado e descrito as cartas e trabalhos do acervo organizado por Bertha Lutz, providenciamos a busca e reprodução de materiais que ela não havia localizado, ou que se tinham extraviado. Em Londres, encontramos no Natural History Museum a correspondência ativa de Lutz com o entomologista Frederick Vincent Theobald. A dra. Charlotte Emmerich, que conviveu com Bertha Lutz, cedeu-nos as cartas escritas por Amy Lutz ao marido, durante a Primeira Guerra Mundial, quando viveu com os filhos em Paris. Em bibliotecas e arquivos do Rio de Janeiro e de São Paulo, localizamos artigos de autoria de Lutz, e recolhemos diversos trabalhos sobre ele, trabalhos que foram lidos, fichados e debatidos pela equipe.

Levantamos, também, a documentação escrita e iconográfica de e sobre Adolpho Lutz nos arquivos e bibliotecas do Rio de Janeiro e de São Paulo.

Uma frente de trabalho importante, ainda em curso, tem sido a coleta de informações sobre seus correspondentes em dicionários e livros biográficos, enciclopédias, obras de referência e livros temáticos. Além de municiar a elaboração da biografia de Adolpho Lutz e dos textos de abertura de cada seção dos trabalhos que estamos editando, a pesquisa é essencial para confirmar ou corrigir nomes capturados, com dificuldade, em documentos manuscritos. A pesquisa é relativamente fácil para personagens que desfrutam de notoriedade no Brasil ou no exterior, e bem mais difícil para aqueles de segundo e terceiro escalão, sabendo-se que as enciclopédias e dicionários em língua inglesa e francesa - conseqüentemente os de língua portuguesa - dão muito mais destaque aos cientistas que atuaram nos países francófonos e anglo-saxões do que aos do mundo germânico, presentes em grande número na correspondência de Lutz.

Estamos realizando pesquisa similar sobre as instituições, sociedades e periódicos científicos que conformam a rede a que ele pertenceu, rede que mudou bastante ao longo das sete décadas de sua vida profissional ativa.

Insumo importante para a realização das metas editoriais e de pesquisa do projeto são as entrevistas com cientistas, familiares e demais pessoas que conheceram Adolpho Lutz, ou que podem fornecer informações sobre seu acervo. Transcrevemos aquela realizada em janeiro de 1996 por Magali Romero Sá e Heloísa Bertol com Esmeraldino Augusto de Souza, auxiliar de Bertha Lutz que participou da transferência do acervo de seu pai para o Museu Nacional. No laboratório de herpetologia encontramos gravações da própria Bertha em antigos rolos magnéticos. A maioria contém registros sonoros de sapos, rãs e pererecas, gravações ao vivo de palestras sobre feminismo ou de roteiros de palestras que faria. Uma fita revelou-se preciosa para nós. Em Lutziana, Bertha Lutz consignou fatos interessantes sobre a história da família e sobre a vida do pai, enunciando de viva voz o roteiro de uma biografia que não chegou a escrever. 
Entrevistamos dois sobrinhos de Adolpho Lutz, William Roberto Lutz e Margareta Luce, que nos cedeu valiosa documentação concernente à família. Entrevistamos, ainda, José de Barros Ramalho Ortigão Junior, que estudou na escola suíço-brasileira fundada pela mãe de Adolpho Lutz e mantida, até a década de 1930, por suas irmãs e sobrinhas. Recolhemos, por fim, valiosas informações sobre o cientista em depoimentos pertencentes ao acervo de história oral da COC.

O principal obstáculo a vencer no projeto Adolpho Lutz e a História da Medicina Tropical no Brasil é o idioma alemão, em que é vazada a fração majoritária do acervo, com numerosos documentos manuscritos em gótico ou em escrita cursiva de difícil leitura.

Não tem sido fácil reunir tradutores com a qualificação necessária para enfrentar estes textos, ademais repletos de nomenclatura zoológica, botânica ou médica historicamente datada, portanto nem sempre disponível nos dicionários de termos técnicos correntes. Estes, por sinal, são escassos nas áreas biológicas. Nossa experiência mostrou que somente certas pessoas mais idosas, de origem alemã, educadas no idioma desde o berço, são capazes de decifrar cartas manuscritas em gótico ou em escrita cursiva antiga. Os tradutores brasileiros ou mesmo alemães mais jovens vencem com lentidão as dificuldades da escrita mais legível e os conteúdos técnicos da correspondência.

A duras penas, e a custo mais elevado do que imaginávamos, temos viabilizado a tradução de parte da correspondência de Adolpho Lutz. Centenas de cartas foram vertidas para o português e, simultaneamente, para um alemão digitado legível. Mais fácil tem sido a tradução dos artigos científicos.

A princípio, nossa estratégia foi selecionar para publicação a parcela mais interessante da correspondência relativa a cada um dos temas que compõem o Acervo Adolpho Lutz. Nossos guias foram o bolsista Paulo Cesar Gil Ferreira Junior, que estudou em escola secundária alemã, e a estudante universitária do curso de literatura alemã Talita Gross, que se dedicaram, intensivamente, à redação de sumários de cada item da correspondência em língua alemã.

Assim, 1.864 dos 3.719 registros criados no banco de dados contêm resumos sobre o conteúdo do documento cadastrado que vão servir, mais tarde, aos usuários do acervo. Têm orientado a escolha das cartas com maior relevância para serem traduzidas na íntegra. Concluímos que seria inviável, face aos prazos e recursos disponíveis, tratar e traduzir o melhor da correspondência relativa a todos os temas. Decidimos privilegiar um universo mais restrito, providenciando a tradução de quase todo o material relativo a ele. Conseguimos, desta maneira, prever de forma mais segura os gastos com tradução.

Decidimos, também, que seriam traduzidos apenas os documentos em alemão. As cartas e os trabalhos escritos em inglês, francês, italiano e 
espanhol serão publicados nestes idiomas. Sempre que possível, faremos a edição bilíngüe dos trabalhos: os que foram traduzidos por iniciativa nossa; os que foram publicados nas Memórias do Instituto Oswaldo Cruz, em alemão e português e, em menor medida, em inglês e português; e aqueles que Bertha e Gualter Lutz traduziram do alemão para o português ou, mesmo, do alemão e/ou português para o inglês.

Concluímos a digitação e tradução dos artigos, manuscritos, relatórios e cartas que vão compor os dois primeiros volumes da obra de Adolpho Lutz. Foram escaneadas as versões originais em alemão e inglês dos trabalhos que vertemos para o português, ou que vieram a lume também neste idioma.

Nossa intenção é combinar os textos em português, com a grafia atualizada, com reproduções fac-similares dos originais nos idiomas estrangeiros em que foram publicados (alemão e inglês, principalmente). Concluímos a revisão final dos trabalhos selecionados para o volume que abarcará as primeiras investigações em história natural e clínica médica de Adolpho Lutz, realizadas em Berna e Leipzig; a tese de doutoramento; os relatórios (muitos inéditos) e a maioria dos trabalhos escritos à época em que esteve à frente do Instituto Bacteriológico de São Paulo; os estudos sobre febre amarela, malária, lepra, cólera, febre tifóide, entomologia, micologia e dermatologia.

Este e os demais volumes conterão também fotografias e fac-símiles de manuscritos e provas tipográficas corrigidas por Adolpho Lutz, bilhetes, cartões, prontuários médicos, protocolos de pesquisa etc.

Os índices onomástico e remissivo estão sendo montados em cada arquivo Word, para serem depois unificados em Page Maker.

Até dezembro de 2002, pretendemos entregar à Editora Fiocruz os originais do primeiro e segundo volumes. O programador visual Fernando Vasconcellos já iniciou o tratamento gráfico das imagens e a elaboração do projeto gráfico, e brevemente iniciará a editoração eletrônica dos textos.

De acordo com o projeto original, os volumes estruturados tematicamente combinariam, em cada seção, os trabalhos inéditos ou publicados com a correspondência relativa ao mesmo tema. Decidimos manter nos dois primeiros volumes apenas as cartas que constituem documentos isolados, reservando as séries de correspondência, que em geral tratam de assuntos variados, para um volume à parte organizado por missivistas, predominantemente.

O critério que presidiu a seleção dos materiais ora destinados a um volume independente foi, no entanto, temático, o que significa dizer que nas pastas associadas aos temas que figurarão nos próximos volumes - helmintologia, tabanídeos, veterinária etc. - encontramse ainda muitas cartas importantes por traduzir ou digitar. O processo de edição destes materiais é mais demorado e espinhoso que o dos trabalhos de Adolpho Lutz, publicados ou inéditos. Algumas das cartas manuscritas em alemão antigo de leitura especialmente difícil ainda 
contêm claros que não puderam ser decifrados pelos tradutores e revisores técnicos, e que demandarão o auxílio de um paleógrafo especializado. A correspondência exige verbetes com informações biográficas que, em muitos casos, terão de ser coligidas em bibliotecas estrangeiras, mais ricas em obras de referência do que as nossas.

Tencionamos dar continuidade ao projeto com a preparação e publicação dos trabalhos e da correspondência de Adolpho Lutz concernentes aos seguintes temas: helmintologia, malacologia, veterinária, entomologia (parte relativa aos tabanídeos), herpetologia, outros domínios da zoologia (aves e mamíferos), botânica e expedições científicas. A biografia de Adolpho Lutz é um trabalho ainda em construção. Certos temas, que não discerníamos com clareza no projeto original, tendem a se transformar em eixos centrais do trabalho com que inauguraremos o primeiro volume da obra do cientista. Seus estudos sobre lepra serão preponderantes. Malária, especialmente a silvestre, e febre amarela, também, havendo um importante traço de união com a primeira doença, já que Lutz defendeu com ardor, até a morte, a teoria de que a lepra era transmitida por mosquitos.

Um tema que se torna cada vez mais importante é a influência alemã na medicina e, em geral, na cultura brasileira durante o tempo de vida de Adolpho Lutz. Herdeiro do legado de Otto Wucherer, ele nos fornece um ponto de vista privilegiado para enxergarmos a teia cada vez mais densa de relações que vão entretecendo os cientistas brasileiros, especialmente os 'germanistas' a que Oswaldo Cruz pertenceu, e os alemães, inclusive os que integraram a expedição enviada ao Brasil no começo do século, cujo relatório, inédito no Brasil, obtivemos no Welcome Institut for the History of Medicine. (Está sendo traduzido e será, em breve, publicado em História, Ciências, Saúde - Manguinhos.) Como se sabe, os alemães tiveram presença marcante no instituto de Manguinhos, à época em que absorveu Adolpho Lutz e em que passou a se chamar Instituto Oswaldo Cruz. A rarefação dos trabalhos publicados em alemão por Lutz e seus pares nas Memórias do Instituto Oswaldo Cruz, a partir da Primeira Guerra Mundial, certamente constitui um indicador importante de mudanças em curso nas relações de ascendência e interlocução entre cientistas brasileiros e estrangeiros no âmbito da microbiologia e medicina tropical.

A elaboração dos textos analíticos ganhou impulso nos últimos meses, dada a possibilidade de utilizarmos as fontes primárias originais que compõem o acervo de Adolpho Lutz, então organizado, ou que vieram sendo recolhidas nas pesquisas em arquivos e bibliotecas, pelos membros da equipe, então liberados da pesada rotina de organização do acervo, prioritária no primeiro ano e meio de projeto. Nossa intenção é produzir dois ensaios sobre Adolpho Lutz e a história da medicina tropical no Brasil. O primeiro, em preparação, abarcará o período que se estende de meados do século XIX até seu ingresso no IOC, e o segundo, daí até sua morte, em 1940. 